\title{
IMUNODEPRESSÃO INDUZIDA POR TALIDOMIDA E CICLOSPORINA EM TRANSPLANTE CARDÍACO HETEROTÓPICO DE COELHO: AVALIAÇÃO DA SOBREVIDA E DA REJEIÇÃO AO ENXERTO
}

\author{
Immunodepression Induced by Thalidomide And Cyclosporine in the Heterotopic Heart \\ Transplantation of Rabbits: Avaliation of Survival and Allograft Rejection
}

João Batista Vieira de Carvalho', Andy Petroianu², Eduardo Travolo ${ }^{3}$,
Alberto Brasil Barbosa Duarte ${ }^{3}$, Benhur Heleno de Oliveira

\begin{abstract}
RESUMO
Introdução: No presente estudo avaliamos a ação imunodepressora da talidomida isolada ou associada à ciclosporina na prevenção da rejeição ao aloenxerto cardíaco heterotópico em coelhos. Métodos: Cinqüenta coelhos foram utilizados, sendo 25 doadores e 25 receptores. Os animais receptores foram divididos em cinco grupos, cada grupo com cinco animais $(\mathrm{n}=5)$ : Grupo I (Controle) - animais nãoimunodeprimidos, Grupo II - animais imunodeprimidos com ciclosporina na dose de $10 \mathrm{mg} / \mathrm{kg} / \mathrm{dia}$, Grupo III - animais imunodeprimidos com talidomida na dose de $100 \mathrm{mg} / \mathrm{kg} / \mathrm{dia}$, Grupo IV - animais imunodeprimidos com ciclosporina na dose de $5 \mathrm{mg} / \mathrm{kg} / \mathrm{dia}$ e Grupo V animais imunodeprimidos com ciclosporina na dose de $5 \mathrm{mg} / \mathrm{kg} / \mathrm{dia}$ em combinação com talidomida na dose de $50 \mathrm{mg} / \mathrm{kg} / \mathrm{dia})$. Resultados: A combinação da talidomida com e ciclosporina mostrou o mais baixo escore de rejeição histopatológico $(\mathrm{p}<0,05)$. A talidomida e ciclosporina administradas isoladamente ou em associação foram efetivas contra a rejeição, aumentando significativamente a sobrevida $(\mathrm{p}<0,01)$ dos animais. Conclusão: A talidomida pode ser considerada uma droga imunodepressora eficaz na prevenção da rejeição ao aloenxerto cardíaco heterotópico de coelhos em posição abdominal.
\end{abstract}

Descritores: Talidomida, Ciclosporina, Transplante cardíaco heterotópico, Imunodepressão, Coelhos.

Trabalho realizado nos Departamentos de Cirurgia da Faculdade de Medicina da UFMG e Faculdade de Ciências Médicas, UNIFENAS.

1 Mestre e Doutor em Cirurgia, Professor Adjunto I, Departamento de Cirurgia - Faculdade de Medicina da UFMG; Professor, Angiologista e Cirurgião Cardiovascular - Hospital Universitário Alzira Velano - Faculdade de Ciências Médicas da UNIFENAS;

2 Professor Titular do Departamento de Cirurgia - Faculdade de Medicina da UFMG: Docente-Livre em Gastroenterologia Cirúrgica - Faculdade de Medicina de Ribeirão Preto, USP; Docente-Livre em Técnica Cirúrgica e Cirurgia Experimental - Escola Paulista de Medicina - UNIFESP; Doutor em Fisiologia e Farmacologia - Instituto de Ciências Biológicas da UFMG Pesquisador IA do CNPq;

3 Acadêmico de Medicina - Faculdade de Ciências Médicas de Alfenas, UNIFENAS, MG. Endereço para correspondência: Dr. João Batista Vieira de Carvalho - Rua Domingos Vieira, 587 - sala 1210 B - Santa Efigênia - Belo Horizonte - MG - CEP 31150-240 Fone: (31) 3241-4092 -E-mail: drjoaobvc@uol.com.br

Recebido em: 30/06/2003

Aceito: 09/12/2004

\section{INTRODUÇÃO}

O sucesso atual com o transplante de órgãos deve-se aos avanços na terapia imunodepressora e à disponibilidade de ampla variedade de agentes farmacológicos. ${ }^{1,3} \mathrm{O}$ progresso permitiu passar da terapia inicialmente citotóxica, associada à alta morbidade, para uma voltada à melhor regulação da resposta imune. ${ }^{4,5} \mathrm{~A}$ busca de novas drogas imunodepressoras eficazes e com menor toxicidade constitui um desafio. ${ }^{6,7}$

Um medicamento que parece ter ação imunodepressora é a talidomida.${ }^{8,9}$ Apesar dos primeiros insucessos experimentais, esta droga mostrou-se válida no tratamento da reação enxerto-versushospedeiro, observado no transplante de medula óssea. ${ }^{10,16}$ Estudos experimentais têm evidenciado a ação da talidomida como droga imunodepressora e antiinflamatória em transplantes de órgãos e no tratamento de uma série de doenças. ${ }^{12,16}$

Dessa forma, a talidomida pode representar uma nova opção no campo da imunodepressão farmacológica e no controle da rejeição ao aloenxerto ${ }^{8,17}$ Ela poderia eventualmente substituir os corticóides, pelo menos parcialmente, como droga única ou associada a doses menores de imunodepressores, como a ciclosporina, para reduzir os efeitos adversos deste medicamento. 
Com o objetivo de avaliar a ação imunodepressora da talidomida em nível experimental, realizou-se o presente trabalho.

\section{MATERIAL E MÉTODOS}

Foram utilizados 50 coelhos mestiços, adultos e de ambos os sexos ( 32 machos e 18 fêmeas), sendo 25 doadores e 25 receptores. $O$ peso dos animais variou entre 1,8 e $2,4 \mathrm{~kg}(2,1 \pm 1,8 \mathrm{~kg})$.

Os receptores foram divididos em cinco grupos:

Grupo I: controle, sem imunodepressão.

Grupo II: ciclosporina administrada na dose de $10 \mathrm{mg} / \mathrm{kg} / \mathrm{dia}$.

Grupo III: talidomida administrada na dose de $100 \mathrm{mg} / \mathrm{kg} / \mathrm{dia}$.

Grupo IV: ciclosporina administrada na dose de $5 \mathrm{mg} / \mathrm{kg} / \mathrm{dia}$.

Grupo V: ciclosporina administrada na dose de $5 \mathrm{mg} / \mathrm{kg} /$ dia associada à talidomida na dose de $50 \mathrm{mg} / \mathrm{kg} / \mathrm{dia}$.

Os medicamentos foram administrados por cateter orogástrico no dia anterior à operação e nos dias subseqüentes ao pós-operatório. O acompanhamento dos animais estendeu-se até o óbito deles ou até a cessação dos batimentos cardíacos no coração transplantado, quando então os animais foram sacrificados e as vísceras colhidas para exame histopatológico.

Os animais foram submetidos à anestesia geral endovenosa com punção da veia marginal da orelha e injeção de pentobarbital sódico (Hypnol ${ }^{\circledR}$, Laboratório Cristália, Itapera, SP) na dose de $30 \mathrm{mg} / \mathrm{kg}$. A anti-sepsia foi feita com solução alcoólica de iodo a $2 \%$, após adequada tricotomia do tórax e abdome.

O procedimento cirúrgico no doador obedeceu as seguintes etapas:

Procedeu-se à abertura longitudinal das cavidades torácica e abdominal desde o manúbrio esternal até a sínfise púbica, com bisturi de lâmina ํㅡㄴ 22. O pericárdio foi aberto, e o coração e grandes vasos foram dissecados. As veias cavas cranial e caudal foram ligadas com fio de seda 2-0 e seccionadas. Dissecou-se a aorta e o tronco pulmonar. Um cateter calibre $27 \mathrm{G}$ foi introduzido na porção alta da aorta ascendente para injeção da solução cardioplégica de Saint Thomas a $4^{\circ} \mathrm{C}$ (Quadro I) e de $0,3 \mathrm{ml}$ de heparina sódica (Liquemine ${ }^{\circledR}$, Laboratório Roche, 5000 UI / ml, São Paulo). Após a parada do coração em diástole, a aorta e o tronco pulmonar foram ligados com seda 2-0, cranialmente, próximo aos ramos arteriais, a $4,0 \mathrm{~cm}$ do coração. Em seguida, o coração e os grandes vasos foram removidos. As veias e artérias pulmonares foram ligadas com seda 4-0 junto ao hilo pulmonar. Os pulmões foram separados do bloco coração-pulmão por meio de secção dos vasos do pedículo pulmonar. $\mathrm{O}$ coração doador foi conservado em solução de cloreto de sódio a $0,9 \%$, a $4^{\circ} \mathrm{C}$, até o seu implante no receptor.

No dia anterior ao procedimento cirúrgico, os animais receptores receberam a medicação imunodepressora via oral, através de cateter orogástrico, na dosagem preconizada em cada grupo. Essa medicação foi administrada seis horas antes do transplante e mantida durante o pós-operatório, pelo período estabelecido. O transplante cardíaco heterotópico foi realizado com implante do enxerto nos vasos abdominais (aorta e veia cava inferior) do receptor. A aorta do doador foi anastomosada à aorta abdominal do receptor, com sutura término-lateral, contínua, utilizando fio de Prolene 7-0. $\mathrm{O}$ tronco pulmonar do coração doador foi anastomosado à veia cava caudal do receptor com sutura término-lateral contínua utilizando fio de Prolene ${ }^{7,0}$ ( Figura 1 ). ${ }^{1}$

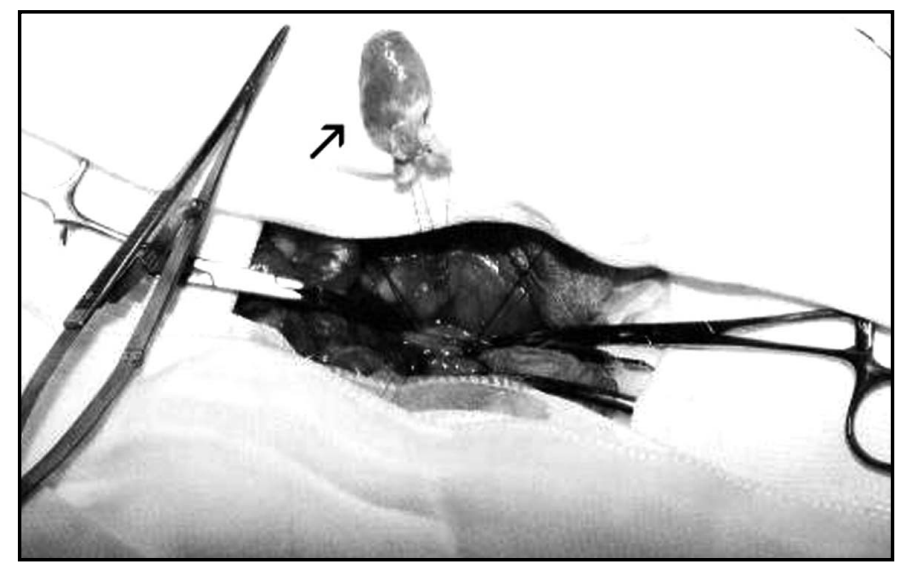

Figura 1. Transplante cardíaco heterotópico (*) em posição abdominal.

Os movimentos respiratórios, coloração das mucosas, batimentos cardíacos nos corações próprio e transplantado foram avaliados em intervalos de 5 minutos até a recuperação da atividade normal, com ritmo e freqüência adequados em cada coelho, ao término da operação. A seguir, os animais foram transferidos para gaiolas adequadas e mantidos aquecidos por holofotes equipados com lâmpadas fluorescentes de 100 Watts de potência. Os animais receberam ração e água previamente filtrada em recipientes próprios.

No pós-operatório, os animais foram pesados diariamente. Observou-se o seu estado geral e, por palpação abdominal, identificou-se a presença de batimentos no coração transplantado. Nos animais imunodeprimidos com ciclosporina mediram-se semanalmente os níveis dessa droga no sangue total por meio de radioimunoensaio (RIE) mantendo-se os níveis entre 150-250 $\mathrm{ng} / \mathrm{ml}$. As drogas imunodepressoras foram mantidas até o óbito ou cessação dos batimentos cardíacos dos animais.

Quando cessaram os batimentos cardíacos no coração transplantado, os animais foram sacrificados com injeção endovenosa de pentabarbital sódico $(30 \mathrm{mg} / \mathrm{kg})$. O coração transplantado, os pulmões e os rins do receptor foram retirados e enviados para exame histopatológico. Os animais que evoluíram para óbito também foram necropsiados e suas vísceras (coração transplantado, pulmões e rins) retiradas e enviadas para exame histopatológico.

Todos os procedimentos envolvendo os animais seguiram rigorosamente os preceitos estabelecidos na Declaração de Helsinque (1965) e no Código Brasileiro de Experimentação Animal (1988). ${ }^{17,19}$

Os órgãos retirados foram fixados em solução de formaldeído a $10 \%$ e posteriormente preparados para avaliação histológica.

O critério de rejeição teve como base a classificação de rejeição ao transplante cardíaco adotada pela International Society for Heart Transplantion, com as modificações da Tabela $1 .^{20,21}$ 
Tabela 1 - classificação da rejeição ao aloenxerto cardíaco modificadada international society for heart transplantation.

\begin{tabular}{lll}
\hline Grau & Nomenclatura nova & Nomenclatura antiga \\
\hline 0 & Sem rejeição & Sem rejeição \\
1 & $\begin{array}{l}\text { Infiltrado local perivascular ou intersticial } \\
\text { Infiltrado difuso disperso sem necrose }\end{array}$ & $\begin{array}{l}\text { Rejeição sem necrose } \\
\text { Rejeição pequena }\end{array}$ \\
2 & $\begin{array}{l}\text { Apenas um foco com infiltração } \\
\text { intensa e/ou lesão focal dos miócitos }\end{array}$ & Rejeição focal moderada \\
4 & $\begin{array}{l}\text { Infiltrados intensos multifocais } \\
\text { ou lesões dos miócitos }\end{array}$ & Rejeição moderada baixa \\
5 & $\begin{array}{l}\text { Processo inflamatório difuso com necrose } \\
6\end{array}$ & $\begin{array}{l}\text { Infiltrado polimórfico agressivo, } \\
\pm \text { infiltrado, } \pm \text { edema, } \pm \text { hemorragia, } \\
\pm \text { vasculite com necrose }\end{array}$ \\
\hline
\end{tabular}

Rejeição "em resolução"- grau menor. Rejeição solucionada - Grau 0.

A rejeição foi classificada nos seguintes graus:

Grau 0: ausência de rejeição; ausência de infiltrado inflamatório perivascular, intersticial, necrose, lesões de miócitos, edema, hemorragia e/ou vasculite .

Grau 1: rejeição; presença de infiltrado local perivascular ou intersticial sem necrose miocitária; ausência de vasculite.

Grau 2: rejeição ligeira; infiltrado inflamatório difuso porém disperso, sem necrose de miócitos ou sinais de vasculite.

Grau 3: rejeição focal moderada; presença de um foco de infiltrado inflamatório intenso e/ou lesões focais de miócitos, sem sinais de vasculite.

Grau 4: rejeição moderada baixa; presença de infiltrado inflamatório intenso multifocal ou lesões dos miócitos; ausência de vasculite.

Grau 5: rejeição limítrofe grave; presença de processo inflamatório difuso com necrose; ausência de vasculite.

Grau 6: rejeição intensa aguda; presença de infiltrado inflamatório intenso difuso, hemorragia e vasculite com necrose.

Como as respostas medidas foram qualitativas (grau de rejeição e sobrevida), os resultados foram submetidos à análise não paramétrica de Kruskal - Wallis com ordenações médias comparadas pelo teste $\mathrm{t}$ de Student. Adotou-se como nível de significância $\mathrm{p}<0,05$.

\section{RESULTADOS}

A sobrevida foi maior $(\mathrm{p}<0,05)$ nos grupos II, III e $\mathrm{V}$ do que nos grupos I e IV (Tabela 2).

Não houve diferença em relação à sobrevida nos grupos II, III e V. Os imunodepressores empregados nesses grupos em associação ou isoladamente, foram efetivos em aumentar a sobrevida dos animais submetidos aos tratamentos (Tabela 2).
Tabela 2 - Tempo médio de sobrevida (dias) e critério médio de rejeição segundo os grupos experimentais

\begin{tabular}{lcc}
\hline Grupos & Tempo de Sobrevida (dias) & Rejeição* \\
\hline GRUPO I & 5,2 & 4,0 \\
GRUPO II & $18,2^{*}$ & $1,4^{*}$ \\
GRUPO III & $17,6^{*}$ & $1,6^{*}$ \\
GRUPO IV & 9,0 & 2,4 \\
GRUPO V & $17,8^{*}$ & 0,4 \\
\hline
\end{tabular}

* Critério médio de rejeição segundo a classificação modificada da Inter national Society for Heart and Lung Transplantation.

* Diferença estatisticamente significativa $(p<0,05$ para tempo de sobrevida e $p<0,01$ para rejeição )

- Grupo I - Controle- Animais não Imunodeprimidos.

- Grupo II - Animais imunodeprimidos com ciclosporina (10 mg/kg/dia).

- Grupo III - Animais imunodeprimidos com talidomida (100 mg/kg/dia).

- Grupo IV - Animais imunodeprimidos com ciclosporina (5 mg/kg/dia).

- Grupo V - Animais imunodeprimidos com talidomida $(50 \mathrm{mg} / \mathrm{kg} / \mathrm{dia})$ e ciclosporina (5 $\mathrm{mg} / \mathrm{kg} / \mathrm{dia})$.

A ocorrência de rejeição foi menor nos grupos II e V. Os três tratamentos foram efetivos no controle da rejeição $(p<0,01)$ (Tabela 2 e Figuras 2 e 3).

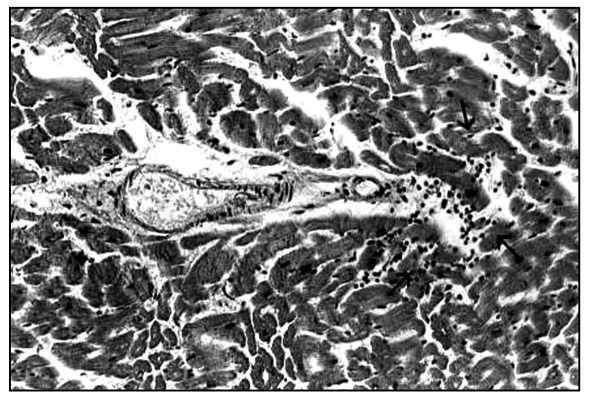

Figura 2. Exame histopatológico do animal imunodeprimido com talidomida - dose de $100 \mathrm{mg} / \mathrm{kg} /$ dia - critério histopatológico de rejeição: 1 . Infiltrado linfocitário intersticial (setas). Hematoxilina - eosina, aumento de $200 x$

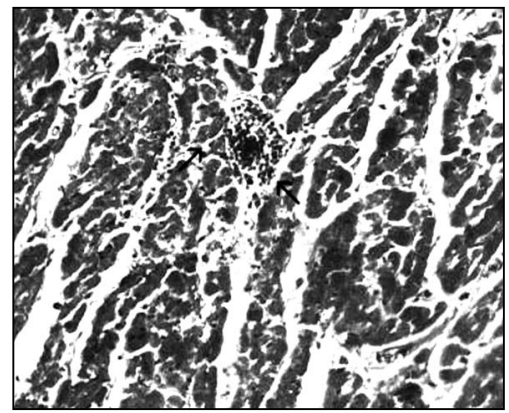

Figura 3. Exame histopatológico de animal imunodeprimido com talidomida e ciclosporina - Critério histopatológico de rejeição: 1. Infiltrado focal sem necrose dos cardiomiócitos (setas). Hematoxilina-eosina, aumento de $100 x$. 
Com base nesta pesquisa, a talidomida na dose de $100 \mathrm{mg} / \mathrm{kg} / \mathrm{dia}$ ou associada à ciclosporina na dose de $5 \mathrm{mg} / \mathrm{kg} /$ dia foi efetiva no controle da rejeição (Tabela 2).

\section{DISCUSSÃO}

A técnica de transplante heterotópico em posição abdominal do aloenxerto cardíaco tem sido utilizada como modelo para estudo da ação farmacológica de medicamentos, hormônios, para verificar a intensidade da lesão miocárdica secundária à reperfusão e do padrão histológico de rejeição ao aloenxerto cardíaco. Esse método é simples e relativamente fácil de ser reproduzido em modelo experimental. ${ }^{22,27}$

Com o objetivo de verificar o comportamento da rejeição e o tempo de sobrevida dos animais, em face de diferentes doses de medicações imunodepressoras, foram empregadas doses diferentes de talidomida e ciclosporina, isoladas ou em associação. Doses menores com resultados aceitáveis em relação ao controle da rejeição e aumento da sobrevida representam redução no custo do procedimento do transplante e menores efeitos adversos relacionados à utilização das drogas imunodepressoras. Em ratos, a associação da talidomida com ciclosporina foi eficaz tanto no tratamento quanto na prevenção dos episódios de rejeição ao aloenxerto cardíaco após indução inicial com ciclosporina. ${ }^{17}$

O presente estudo mostra que a associação da talidomida com a ciclosporina em baixas doses terapêuticas foi tão efetiva quanto o emprego isoladamente de ciclosporina em dose plena. Os mecanismos relacionados ao sinergismo da ciclosporina com a talidomida são desconhecidos, mas existem evidências que sugerem que ambos os medicamentos agem seletivamente em diferentes aspectos da resposta imune do hospedeiro. $8,10,23,28,29,30,31$

O mecanismo de ação da talidomida sobre a imunidade humoral e celular ainda não foi estabelecido. É possível que seus efeitos antiinflamatórios estejam associados à inibição da quimiotaxia dos neutrófilos. ${ }^{28,30}$ Atuação da talidomida na sobrevida dos transplantes de pele em coelhos e sua eficácia na prevenção e tratamento da reação enxerto versus hospedeiro transplante de medula óssea em murinos, são conhecidas. ${ }^{13,14,15,16} \mathrm{~A}$ talidomida associada à ciclosporina reduziu o infiltrado inflamatório intersticial, endocárdico e o processo inflamatório mononuclear perivascular (Figuras 2 e 3). ${ }^{28,31}$

\section{CONCLUSÃO}

A sobrevida dos animais e dos enxertos foi maior após a administração da talidomida, sugerindo um possível efeito dessa droga em retardar a evolução do processo de rejeição. A eficácia da associação da talidomida com a ciclosporina pode representar uma contribuição importante no sentido de uma eventual aplicação como imunodepressor farmacológico em transplantes de órgãos. O emprego em doses eficazes e menores que as convencionais poderia reduzir, pelo menos em parte, os efeitos colaterais dessas drogas. ${ }^{17}$

Estudos futuros são necessários para determinar os mecanismos imunológicos responsáveis pelo sinergismo entre a talidomida e a ciclosporina, bem como para estabelecer seu real papel na farmacoterapia dos transplantes de órgãos.

\section{Fontes financiadoras}

FAPEMIG - Fundação de Amparo à Pesquisa de Minas Gerais.

\section{ABSTRACT}

Introduction: In the present study we evaluated the immunodepressive action of thalidomide alone or in combination with cyclosporine on the prevention of rejection of heterotopic cardiac allografts in rabbits. Methods: Fifty rabbits were used, 25 of them as donors and 25 as recipients. Recipient animals were divided into five groups $(\mathrm{n}=5$ each): Group I (control) - non-immunodepressed animals; Group II, animals immunodepressed with cyclosporine at the dose of $10 \mathrm{mg} / \mathrm{kg}$ /day; Group III, animals immunodepressed with thalidomide at the dose of 100 $\mathrm{mg} / \mathrm{kg} / \mathrm{day}$; Group IV, animals immunodepressed with cyclosporine at the dose of $5.0 \mathrm{mg} / \mathrm{kg} /$ day and Group V, animals immunodepressed with cyclosporine at the dose de $5.0 \mathrm{mg} / \mathrm{kg} / \mathrm{day}$ in combination with thalidomide at the dose of $50 \mathrm{mg} / \mathrm{kg} / \mathrm{day}$. Heart donors were implanted in the abdomen of recipients. Results: The combination of thalidomide and cyclosporine showed the lowest histopathological rejection score $(p<0.05)$. Thalidomide administered alone or in combination with cyclosporine was effective against rejection, significantly increasing the survival $(\mathrm{p}<0.01)$ of animals. Conclusion: Thalidomide should be considered as an effective immunodeppressive drug that play an important role in heterotopic heart allotransplantation in rabitts.

Key words: Thalidomide, Cyclosporine, Heterotopic heart transplantation, Immunodeppression, Rabbits.

\section{REFERÊNCIAS}

Mann, F.C.; Priestley, J.T.; Markowitz, U.; et al. Transplantation of the intact mammalian. Heart Ann Surg 1933; 26: 219-24.

2 Belaube, P.; Garcin, G.; Marchand, J.P.; Privat, Y. Should thalidomide be rehabilited? Sem Hop 1983; 59: 3101-4.

3 Calne, R.Y.; Collier, D.S.; Lim,S; et al. Rapamycin goes immunosupression in organ allografting. Lancet 1989; 2: 227.

4 Cosenza, C.A.; Cramer, D.U.; Tuso, P.J.; et al. Combination therapy with cardiac xenograft survival. J Heart Lung Transplant 1994; 13: 489-97.

5 Cramer, D.V.; Chapman, F.A.; Jaffe, B.D.; et al. The effect of the new immunosuppressive drug, brequinar sodium, on heart, liver and kidney allograft rejection in the rat. Transplantation 1992; 53: 303 .

6 Fujino, Y.; Kawamura, T.; Hullett, D.A.; et al. Evaluation of cyclosporine, mycophenolate mofetil, and brequinar sodium combination therapy on hamster to rat cardiac xenotransplantation. Transplantation 1994; 57: 41.

7 Nelson, P.W. Cyclosporine. Surg Gynecol Obstet 1984; 159: 297-308.

8 Barnhill, R.L.; Doll, N.J.; Millikan, E.; et al. Studies on the anti inflammatory properties of thalidomide. J Am Acad Dermatol 1984; 11: 814 - 9.

$9 \quad$ Bore, P.J.; Scothorne, R.J. Effect of thalidomide on survival on skin homografts in rabbits. Lancet 1966; 1: 1240-1. 
10 Gutierrez-Rodriguez, O. Thalidomide: the promising new treatment goes rheumatoid arthritis. Arth Rheum 1984; 27: 1118.

1 Hellman, K.; Duke, O.I.; Tucker, D.Z. Prolongation of skin homograft survival by thalidomide. Br Med J 1965; 2: 687 .

12 Mouzas, G.L.; Gershon, R.K. The effect of thalidomide on skin allografts in mice survival of the grafts. Transplantation 1968; 6: 476-8

13 Parker, P.M.; Ground, N.; Nademanee, A.; et al. Thalidomide the salvage therapy goes chronic graft-versus-host disease. Blood 1995; 86: 3604-9.

14 Vogelsang, G.B.; Hess, A.D.; Saints, G.W. Thalidomide goes treatment of graft versus - host disease. Bone Marrow Transplant 1988; 3:393 - 8. treatment of chronic graft - versus - host disease. N Engl. J Med 1992; 326:1055-8.

15 Vogelsang, G.B.; Hess, A.D.; Gordon, G.; et al. Treatment and prevention of acute graft-versus-host disease with thalidomide in a rat model. Transplantation 1986:41:644-7

16 Wood, P.M.; Proctor, S.J. The potential uses of thalidomide in the therapy of graft - versus - host disease. the review of clinical and laboratory information. Leuk Res 1990; 14: 395-9.

17 Emre, S.; Sumrani, N.; Hong, J. Beneficiary effect of thalidomide and ciclosporin combination in heterotopic cardiac transplantation in rats. Eur Surg Res 1990; 22: 336-9.

18 HOFF, C. Immoral moral and uses of animals. N Eng J Med 1980; 302: 115-8

19 Petroianu, A. Ethical aspects in the research in animals. Acta Cir Bras 1996; 11.

20 Billingham, M.E.; Cary, N.R.B.; Hammond, M.E.; et al. The formulating goes the standardization of nomenclature in the diagnosis of heart and lung rejection: J.Heart Transplant 1990; 9: 588.

${ }^{21}$ Billingham, M.E. Pathology and etiology of chronic rejection of the heart. Clin Transplant 1994; 8: 289-92.

22 Petroianu, A. Transplants intestinal. Revista de Cirurgia do Hospital Mater Dei $1988 ; 1-2$.

23 Kawahara, K.; Stuherland, D.E.; Rynasiewicz, J.J.; et al. Prolongation of heterotopic cardiac allografts in rats by cyclosporin A. Surgery 1980; 88: 594-600.

24 Giardina, J.J.; Malinowaka, K.; Pizarre, R.; et al. Use of cyclosporine in the mouse heterotopic heart transplant model. J Heart Transplant 1990; 9:106-13.

25 Babuty, D.; Aupart, M.; Cosnay, P.; et al. Electrocardiographic and eletro - physiologic properties of cardiac allografts. J Cardiovasc Electrophysiol 1994;5:1053-63.

26 Amirhamzeh, M.M.; Jia, C.X.; Starr, J.P.; et al. Diastolic junction in the heterotopic rat heart transplant model. Effects of edema, ischemia, and rejection. J Thorac Cardiovasc Surg 1994; 108: 928-37.

27 Korecky, B.; Masika, M. Uses of the heterotopic cardiac isotransplant it goes pharmacological and toxicological studies. Toxicol Pathol 1990; 18: 541-6.

28 Maurice, P.D.; Barkley, A.S.; Allen, B.R. The effect of thalidomide on arachidonic acid metabolism in human polymorphonuclear leukocytes and latelets. Br J Dermatol 1986; 115: 677-80.

29 Keenan, R.J.; Eiras, G.; Burckart, G.J.; et al. Immunossupressive properties of thalidomide. Inhibition of in vitro lymphocytes proliferation done and in combination with cyclosporine or FK506. Transplantation 1991; 52: 908-10.

30 Aronson, I.K.; Webber, L.; West, D.; et al. Thalidomide and lymphocyte function J Am Acad Dermatol 1986; 14: 282-3.
31 Gusdon, J.P.; Cohen, C. Effect of thalidomide on the antibody response. Am Obstet Gynecol 1968; 100: 952

32 Chen, T.L.; Vogelsang, G.B.; Petty, B.G.; et al. Plasm pharmacocinetic and urinary excretion of thalidomide after oral dosing in healthy male volunteers. Drug Metab Disposed 1989; 17: 402-5.

33 Czejka, M.I.; Koch, H.P. Determination of thalidomide and its major metabolites by hygh-performance chromatography. J Chromatogr 1987; 413:181-7.

34 Eriksson, T.; Bjorkman, S.; FYGE, A.; et al. Determination of thalidomide in plasm and blood by high-performance liquid chromatography: avoiding hydrolitic degradation. J Chromatogr 1982, 582, 211-6.

11. Viklicky O, Malt I, Voska L, Bohmova R, Lacha J, Lodererova A, et al. TGF-beta1 and chronic allograft nephropathy in protocol kidney graft biopsy. Physiol Res 2003;52(3):353-60.

12. Bauer JH, Reams GP. The angiotensin II type 1-receptor antagonists: a new class of antihypertensive drugs. Arch Intern Med 1995;155:1361-9.

13. Mas V, Alvarellos T, Giraudo C, Massari P, De Boccardo G. Intragraft messenger RNA expression of angiotensinogen: relationship with transforming growth factor beta-1 and chronic allograft nephropathy in kidney transplant patients. Transplantation 2002;74(5)718-21.

14. Tanabe S, Nakatany T, Han Y, Kishimoto T, Ohishi M, Ogami M, et al. Enhanced expression of angiotensin II type 1 receptor in the neointima of transplant renal arteriosclerosis in human renal allografts. XVIII International Congress of the Transplantation Society 2000;OAP85 10.10:0654

15. Shihab FS, Bennett WM, Tanner AM, Andoh TF. Angiotensin II blockade decreases TGF-betal and matrix proteins in cyclosporine nephropathy. Kidney International 1997;52(3):660-73.

16. Ling H, Li X, Jha S, Wang W, Karetskaya L, Pratt B, et al. Therapeutic role of TGF- $\beta$-neutralizing antibody infecção mouse cyclosporin A nephropathy: morphologic improvement associated with functional preservation. J Am Soc Nephrol 2003;14:377-88.

17. Stigant CE, Cohen J, Vivera M, Zaltzman JS. ACE inhibitors and angiotensin II antagonists in renal transplantation: an analysis of safety and efficacy. Am J Kidney Dis 200;351);58-63.

18. Amuchastegui SC, Azzollini N, Mister M, Pesota A, Perico N, Remuzzi G. Chronic allograft nephropathy in the rat is improved by angiotensin II receptor blockade but not by calcium channel antagonism. J Am Soc Nephrol 1998;9:1948-55.

19. Farzad Z, Nagano H, Kusaka M, Coito AJ, Troy JL, Nadeau KC, et al. Renal allograft protection with losartan in Fisher->Lewis rats: hemodynamics, macrophages, and cytokines. Kidney International 2000;57(6):2618-25.

20. Campistol JM, Inigo P, Jimenez W, Lario S, Clesca PH, Oppenheimer F, et al. Losartan decreases plasma levels of TGF-b1 in transplant patients with chronic allograft nephropathy. Kidney International 1999;56:714-9.

21. Hetzel GR, Hermsen D, Hohfeld T, Rettich A, Ozcan F, Fussholler A, et al. Effects of candesartan and perindopril on renal function, TGF-betal plasma levels and excretion of prostaglandins in stable renal allograft recipients. Clin Nephrol 2002;57(4):296-302.

22. Agarwal R, Siva S, Dunn SR, Sharma K. Add-on angiotensin II receptor blockade lowers urinary transforming growth factor-beta levels. Am J Kidney Dis 2002;39(3):486-92.

JBT J Bras Transpl 2004; 7:188-192 